\title{
A INCLUSÃO NA PRÁTICA: ALUNOS COM DEFICIÊNCIA NO ENSINO SUPERIOR
}

\author{
INCLUSIÓN EN LA PRÁCTICA: LOS ESTUDIANTES CON DISCAPACIDAD EN \\ LA EDUCACIÓN SUPERIOR
}

\author{
INCLUSION IN PRACTICE: STUDENTS WITH DISABILITIES IN HIGHER \\ EDUCATION
}

\author{
Danielle S. Pinheiro WELLICHAN ${ }^{1}$ \\ Camila da Silva SOUZA ${ }^{2}$
}

\begin{abstract}
RESUMO: Incluir quem não deveria ter sido excluído, esse é o caminho que a sociedade deveria seguir, no entanto, ainda é possível presenciar o quanto estamos longe de uma igualdade de direitos em diversos segmentos da humanidade. $\mathrm{Na}$ área educacional, no ensino superior por exemplo, o crescente aumento no número de matriculas no âmbito universitário demonstram o quanto as pessoas com deficiências podem ir longe, desmistificando anos da história de exclusão. E para que essa inclusão de fato aconteça é necessário voltar o olhar para o que antes era foco da educação básica, repensando todo o conceito de acessibilidade, práticas e convivência, revendo o espaço do Ensino Superior como um todo. Por meio da revisão de literatura, buscou-se construir o referencial deste trabalho para propor novas discussões e olhares a respeito da inclusão nas universidades.
\end{abstract}

PALAVRAS-CHAVE: Inclusão. Pessoas com deficiência. Ensino Superior.

RESUMEN: Incluir que no debería haber sido eliminado, el camino que debe seguir la sociedad, sin embargo, todavía es posible ver cuánto estamos lejos de la igualdad de derechos en diversos segmentos de la humanidad. En la educación, en la educación superior, por ejemplo, aumentar el número de matrículas en las universidades demuestran la cantidad de gente con discapacidades pueden ir muy lejos, desmitificando años de historia de exclusión. Y por ese hecho la inclusión suceda es necesario volver a examinar lo que fue el foco de la educación básica, replantear todo el concepto de accesibilidad, las prácticas y la convivencia, la revisión del área de la educación superior en su conjunto. A través de revisión de la literatura, hemos tratado de construir el marco de este trabajo para proponer nuevas discusiones y se ve sobre la inclusión en las universidades

PALAVRAS-CLAVE: Inclusión. Personas con discapacidad. Educación Superior.

ABSTRACT: Including those who should not have been excluded, this is the way that society should follow, however, it is still possible to witness how far we are from an

1 Mestra em Ciência da Informação pela Unesp/Marília e graduanda em Pedagogia. E-mail: dany_unesp@yahoo.com.br

${ }^{2}$ Pós-graduanda em Metodologia do Ensino a Distância. E-mail: camilasouza.advsp@gmail.com 
equal rights in several segments of humanity. In higher education, for example, the growing number of enrollments at university level shows how people with disabilities can go far, demystifying years of exclusion history. And for this inclusion to happen, it is necessary to turn our gaze to what was once the focus of basic education, rethinking the whole concept of accessibility, practices and coexistence, revising the space of Higher Education as a whole. Through the literature review, we sought to construct the referential of this work to propose new discussions and perspectives regarding inclusion in universities.

KEYWORDS: Inclusion. Disabled people. Higher education.

\section{Introdução}

Fruto de um longo processo histórico, a discriminação, exclusão social e desrespeito aos direitos das pessoas com deficiência, são fatos que se arrastam desde a antiguidade.

$\mathrm{Na}$ Grécia antiga, as crianças nascidas com alguma deficiência eram abandonadas ou até mesmo mortas por seus pais que desejavam crianças saudáveis e fortes, capazes de integrar o exército (AMIN, 2008, p. 3), existindo local específico para tal atrocidade, "um precipício nas cercanias do Monte Taigeto, onde as mães espartanas lançavam seus filhos imperfeitos" (CAVAZZANI, 2005, p.23). Ao passo que em Roma, a discriminação era motivada por crenças e superstições, já que os romanos consideravam que os recém-nascidos "imperfeitos" levavam má-sorte para suas famílias e, portanto, tinham o mesmo fim trágico das crianças gregas.

Embora em uma proporção muito menor que a exposta acima, ainda hoje pessoas com deficiência sofrem condutas discriminatórias que afrontam seus direitos e obstam o exercício da cidadania, inerentes a condição humana.

A Declaração de Salamanca em 1994, permitiu a abertura de novos caminhos para importantes transformações na sociedade e na educação de pessoas com deficiência. Conforme defendido na declaração, a educação é direito fundamental e para todos deve ser dada a oportunidade de atingir e manter o nível adequado de aprendizagem. Foi considerada como uma decorrência da Declaração Mundial sobre a Educação para Todos em 1990 na Tailândia (Declaração de Jomtien), vista pelo aspecto de atender e estabelecer normas ou orientações para os portadores de deficiência. Sendo assim, em meio a muita luta, transpôs-se o paradigma de mudar ou adequar a pessoa, para mudar a escola a fim de receber os alunos independente da necessidade que tenha. Parece simples, mas na realidade a prática é outra, embora existam políticas que 
defendam os direitos e estabeleçam normas para a inclusão, ainda há muito o que ser feito para que a educação se torne de fato para todos, em qualquer âmbito da educação.

Chegar ao ensino superior é uma vitória para grande parcela da população brasileira, se estas forem portadoras de deficiência a situação complica um pouco mais, pois ainda há muito desconhecimento e despreparo no Ensino Superior para receber e manter um universitário com deficiência. Dados da UNICEF revelam que ter alguma deficiência quadriplica a probabilidade "de um adolescente chegar aos 17 anos ainda analfabeto", bem como que, "40\% (quarenta por cento) de todas as crianças e adolescentes que estão fora da escola são deficientes (AUAD; CONCEIÇÃO, 2009).

Assim, discutir a importância da inclusão do aluno com deficiência no Ensino Superior é o principal objetivo deste artigo, que busca na literatura da área da Educação e do Direito subsídios para seu referencial teórico, por meio de uma pesquisa bibliográfica com abordagem qualitativa. Espera-se que o conteúdo aqui reunido e apresentado possa de alguma forma contribuir para a discussão e reflexão da parcela crescente de novos alunos para as instituições de Ensino Superior de forma a auxiliar ambos na busca pela inclusão na prática.

\section{Contextualizando o aluno com deficiência}

A Convenção das Nações Unidas (ONU) define que as pessoas com deficiência são aquelas que têm impedimentos (longo prazo) de natureza física, intelectual, sensorial (visual ou auditiva) ou múltipla, e que podem obstruir de alguma forma a participação delas diante da sociedade em igualdade de condições com as demais. Na atualidade representam aproximadamente 650 milhões de pessoas com alguma deficiência, transtorno global de desenvolvimento (TGD) ou com alta habilidade/ superdotação (AH/SD) com baixas perspectivas de escolaridade, na economia e na saúde (CARVALHO, 2015).

A deficiência de natureza física está ligada as alterações completas ou parciais de um ou mais segmentos do corpo humano, comprometendo a função física de forma congênita ou adquirida (exceto deformidades estéticas ou as que não produzem dificuldades no desempenho das funções).

A pessoa com deficiência intelectual (que por longa data foi também conhecida como "deficiência mental"), possui incapacidade caraterizada por limitações significativas no funcionamento intelectual (raciocínio, aprendizagem ou resolução de 
problemas) como também no comportamento adaptativo, que abrange habilidades sociais, cotidianas e práticas. Por muito tempo, as pessoas com transtorno funcional especifico (Transtornos de Déficit de Atenção e Hiperatividade - TDAH, dislexia, disortografia, disgrafia, discalculia ou dislexia) também foram classificadas como deficientes intelectuais, porém, estudos demonstraram que se tratavam de distúrbios de aprendizagem e por isso a identificação do problema favorece o aprendizado a partir do momento que estratégias de ensino e aprendizagem são elaboradas e direcionadas de forma especifica.

Entre as deficiências sensoriais estão a auditiva (quando o diagnóstico aponta a perda bilateral, parcial ou total de 41 decibéis ou mais, aferidos em audiogramas com frequência de 500 a $3000 \mathrm{~Hz}$; e visual (pessoas cegas, cuja acuidade é igual ou menor que 0,5 no melhor olho - com a melhor correção ótica), ou pessoas com baixa visão cuja acuidade visual varia entre 0,3 e 0,05 no melhor olho (também com a melhor correção ótica), ou quando há a somatória da medida do campo visual em ambos olhos for igual ou menor que $60^{\circ}$ ou de forma simultânea em qualquer situação anterior.

Os Transtornos Globais do Desenvolvimento (TGD) formam também uma categoria que pode estar nas universidades, onde estão agrupados transtornos que apresentam funções do desenvolvimento afetadas em comum, é o caso de pessoas diagnosticadas com o Autismo, Síndrome de Asperguer, Síndrome de Rett e Transtornos Desintegrativos da Infância. Já as pessoas com altas habilidades/superdotação demonstram potencial elevado em qualquer área (intelectual, psicomotora, liderança, arte, além da alta criatividade) de forma isolada ou combinada.

O grande desafio que as universidades no Brasil enfrentam diante das pessoas com deficiência na atualidade envolve a questão da democratização do acesso e a garantia da qualidade no ensino superior, tendo em vista que se a educação é direito de todos é preciso que esteja de fato ao alcance. Mais do que quebras de paradigmas diante da pessoa com deficiência, é preciso que existam avanços nas práticas políticas para que barreiras como preconceito, discriminação e segregação não definam as relações humanas (MUTO; CAMPOS; MELO, 2016). Diante disso, estar ciente das necessidades desses alunos no Ensino Superior pode auxiliar não só os alunos quanto a própria instituição e comunidade acadêmica local na busca pela inclusão, o que será apresentado a seguir. 


\section{O aluno com deficiência no Ensino Superior}

No contexto educacional, tomando como base a Política Nacional de Educação Especial reconhecida pelo Ministério da Educação (2008), para que uma instituição de ensino seja considerada como inclusiva é preciso mais do que a eliminação de barreiras arquitetônicas, a concepção de inclusão precisa envolver o respeito pelas diferenças e pela diversidade, incluindo mudanças de postura profissional e consequentemente de toda comunidade local (colaboradores, corpo docente e discente). Independente da natureza da instituição: pública ou privada, as oportunidades precisam existir, bem como adaptações, reformas, construções, aquisições e disponibilização de tecnologia e recursos pedagógicos a fim de oferecer condições para o acesso e permanência do aluno na universidade. O recorte que se faz neste artigo, é que em instituições públicas os processos vão depender de políticas e resoluções administrativas e financeiras que não serão aqui discutidas, mas as necessidades apontadas se estendem as duas instancias.

Tomando como cenário demonstrativo uma instituição de ensino particular, logo no momento do ingresso, a instituição precisa estar atenta oferecendo informações não só sobre o curso, mas também sobre os recursos disponíveis para que o aluno possa se desenvolver e atender às práticas do curso escolhido. Nesse sentido, algumas universidades estão buscando atentar-se as tais demandas e criaram núcleos e grupos específicos para atender e orientar alunos e professores no processo de inclusão universitária, afinal é preciso estar claro que os objetivos pedagógicos traçados para um aluno com deficiência precisam ser os mesmos que os traçados para alunos sem deficiência, a diferença nesse meio serão os métodos e as estratégias adotadas para alcança-los dentro das particularidades de cada um (DEIMLING; MOSCARDINI, 2012)

Para todos os tipos de deficiência há particularidades que precisam ser consideradas a fim de incluir tais alunos no ambiente, atender as indicações sobre as adequações estruturais e físicas indicadas pela NBR9050 é de extrema importância, além de oferecer a sinalização pensando em informações práticas e claras para todos os tipos de deficiência. Baseado na literatura utilizada para este artigo, segue a seguir algumas recomendações para cada deficiência que podem auxiliar no processo de inclusão universitária:

- Deficiência física: inicialmente é preciso verificar qual é a necessidade do aluno (espaço físico, recurso pedagógico ou mobiliário adequado), além de verificar se 
há necessidade de disponibilizar leitor/transcritor para a realização de provas, inclusive no vestibular, se este for o meio de acesso inicial ao ensino superior. Estando na universidade, o aluno vai precisar utilizar vagas em estacionamento sinalizadas, telefones públicos em altura acessível, rampas e elevadores, além de banheiros, mesas, cadeiras, balcão de atendimento, laboratórios e recursos pedagógicos adaptados e de acessibilidade ao computador (software especiais, equipamentos de entrada e saída etc.). Nas bibliotecas, é preciso espaço suficiente para que possa circular pelo espaço sem que se machuque ou encontre dificuldade quanto a disposição do mobiliário. Em todos os momentos é preciso lembrar da importância da autonomia do indivíduo, portanto, é preciso saber quais as necessidades e estar pronto a oferecer sem que isso represente fazer por ele.

- Deficiência intelectual: devido a sua especificidade, alunos com deficiência intelectual exigem diferentes estratégias de ensino e aprendizagem, nesse caso, oferecer ao aluno um número reduzido de disciplinas por semestre pode auxiliar no desenvolvimento do curso, além disso, um lugar mais próximo ao professor pode contribuir para um melhor acompanhamento do rendimento do aluno. O papel do professor nesse caso é determinante, pois estímulos, compreensão, motivação, identificação das dificuldades e orientação são fatores que contribuem para o respeito à diversidade na sala de aula e demais ambientes. A aprendizagem cooperativa (trabalho em grupo, por exemplo) favorece as aulas práticas e os relacionamentos entre pessoas com e sem deficiência, desde que acompanhado pelo professor para que não tenha distorções nesse sentido. O desenvolvimento de conceitos precisa ser bem trabalhado e por isso, o professor em sala precisa estar atento para disponibilizar modelos e materiais de apoio que podem auxiliar o aluno nessa construção.

- Deficiência auditiva: o intérprete de Libras precisa existir dentro da universidade, e no caso do aluno com deficiência auditiva é preciso verificar a necessidade dele em sala de aula ou na resolução e acompanhamento de questões que possam vir a surgir no ambiente. É preciso lembrar que a língua portuguesa é sua segunda língua em alguns casos e por isso, o cuidado na exigência em avaliações precisa ser considerado e não esquecido. Nessa deficiência a disponibilização de recursos pedagógicos vai depender das necessidades que o aluno tiver, no entanto, cuidados simples precisam ser tomados tanto em sala de aula quanto na convivência de forma geral: falar pausadamente e sempre de frente para o aluno com a deficiência contribui para seu entendimento, uma vez que a leitura labial é também utilizada. A 
questão de termos técnicos específicos de cada área precisam ser acompanhados pois dificuldades na compreensão de conteúdos podem comprometer o aprendizado, uma vez que podem ser inexistentes pela linguagem dos sinais.

- Deficiência visual: para essa deficiência além dos fatores físicos e estruturais que podem representar facilitações ou dificuldades para o acesso ao campus e demais dependências, o aluno com deficiência visual vai precisar de recursos pedagógicos (softwares específicos (DosVox, Virtual Vision, NVDA, entre outros), provas em formato digital para realização em computadores com ledor/transcritor, por exemplo, material em fonte ampliada, fones de ouvido, material em Braille...). É preciso desde o primeiro momento verificar quais as necessidades desse aluno para que os recursos fiquem disponíveis e caso ainda não existam ali sejam providenciados pela administração do campus o quanto antes. Para as bibliotecas, além da estrutura física favorável e dos recursos tecnológicos e pedagógicos já citados acima, é possível disponibilizar materiais em áudio ou em Braille (A Fundação Dorina Nowill, por exemplo, fornece mediante cadastro tais materiais que podem compor o acervo local). $\mathrm{O}$ ambiente precisa favorecer sua interação com autonomia, dessa forma, as adaptações que foram citadas no item de deficiência física também atendem ao deficiente visual em muitos momentos. Quanto a convivência, é importante perguntar ao aluno como pode ser ajudado, ele que deve direcionar a ajuda a sua necessidade. Desfazer o mito de que "todo cego é também surdo" precisa ser trabalhado com a comunidade local, além de conscientizar sobre orientar a pessoa com clareza e precisão, evitando termos como "ali", "aqui", "lá" contribuem para o melhor desenvolvimento do aluno e de sua autonomia.

Atualmente, o Ensino Superior precisa pensar em alunos com Transtornos Globais de Desenvolvimento (TGD) que também fazem parte do público da Educação Especial. $\mathrm{O}$ indicado para eles é que verifique junto ao aluno ou acompanhante a necessidade que possui, no entanto, cuidados como sinalização clara e objetiva (com figuras de apoio para auxiliar na associação das ideias), comunicação clara sem uso de metáforas, além de evitar mudanças bruscas no ambiente sem devida comunicação (mudanças de sala por exemplo) favorecem a convivência entre o aluno e a comunidade local. Em sala de aula, independentemente do tipo de limitação que o transtorno apresente, o incentivo à convivência, a atenção e estimulo ao desenvolvimento do aluno e os cuidados na comunicação (clareza e objetividade) contribuem para que o aluno se sinta parte do ambiente e se desenvolva. 
Alunos com altas habilidades ou superdotação não podem ser tradados com superioridade em detrimento de outros, por isso precisam ser tratado como os demais. A maior preocupação com tal aluno é a adequação curricular que precisa ser diferenciada e motivadora a fim de que esse aluno não desista do curso. Promover desafios, incentivar a produção de pesquisas, assim como oferecer métodos e técnicas a fim de incrementar os conteúdos de sala e o acompanhamento frequente do desenvolvimento de tais alunos podem trazer bons resultados tanto para o aluno quanto para a instituição.

A questão do tempo de duração das avaliações é um fator importante que precisa ser bem pensado antes de ser definido, pois algumas deficiências (e transtornos) vão exigir um tempo maior devido ao uso de recursos na realização ou as próprias limitações de cada um. Diante disso, é preciso bom senso e respeito para não causar constrangimento ou a exclusão antecipada do processo. É preciso lembrar também que a dificuldade na fala vai estar presente em uma ou mais associações de deficiência (ou transtorno) e diante disso, é preciso logo no primeiro momento verificar qual o meio de comunicação utilizado pelo aluno a fim de a partir dali oferecer o atendimento e apoio necessário.

Para todos os casos citados acima, a comunicação ao corpo docente e administrativo sobre a existência desse aluno com suas particularidades e necessidades esclarecidas vai contribuir para que a inclusão aconteça sem constrangimentos ou desconhecimentos. Vale dizer, que a inclusão não pode (e nem deve) ser vista como um ato assistencialista, pois trata-se de um direito que precisa ser praticado e respeitado, portanto, a capacitação profissional é algo que precisa ser apoiada e trabalhada em prol de bons resultados. Por isso, torna-se essencial refletir sobre a prática pedagógica e administrativa na política inclusiva, pois somente mediante o envolvimento de todos aliado as adaptações/adequações sobre as condições existentes no ambiente é que a prática inclusiva de qualidade pode acontecer (FREITAS; TEIXEIRA, RECH, 2016). Assim, a formação docente novamente abre espaço para discussão uma vez que precisa ser tratada e trabalhada de forma significante para estar atualizada diante dessas novas demandas (PERTILE; ROSSETTO, 2015).

Por muito tempo a luta pela inclusão ocorreu visando a educação básica (Educação Infantil, Ensino Fundamental e Médio), no entanto a legislação garante a educação em todos os níveis educacionais buscando oferecer condições para o acesso, permanência e desenvolvimento de pessoas com deficiência por meio da Política Nacional de Educação Especial na Perspectiva da Educação Inclusiva (BRASIL, 2008). 
Dados estatísticos divulgados no Censo do Ensino Superior de 2014 apontam o crescimento de $438 \%$ de matriculas nas universidades, sendo 16.790 em instituições particulares e para atender a esse público a universidade precisa se organizar e oferecer um ambiente acessível para que o aluno possa desenvolver seus estudos (BAU, 2015).

O crescimento desse público no Ensino Superior comprova a necessidade de práticas inclusivas urgentes a fim de oferecer condições para que os estudos prossigam para eles, evidenciando a transversalidade da educação especial, efetivada por meio de ações que envolvem o planejamento e a organização de recursos e serviços para a acessibilidade, comunicação e desenvolvimento de forma geral, a exemplo disso, estão as salas de recursos e métodos didáticos tecnológicos e a metodologia diferenciada além do atendimento especializado que não são mais exclusividades da educação básica e também está sendo oferecidos nas universidades (BRASIL, 2008). Assim, considerar as diferentes formas de aprender, respeitar a diversidade e aceitar a diferença baseando-se em metodologias que unifiquem a teoria e a prática não só contribuem para a inclusão como diminuem as chances de evasão da pessoa com deficiência na universidade (CANDIDO; NASCIMENTO; MARTINS, 2016).

A sociedade atual exige que os períodos de segregação, exclusão, e integração sejam abandonados para que a inclusão possa de fato acontecer, e só se adequando às necessidades especificas de seus alunos é que será possível garantir os princípios de igualdade, equidade e justiça social (VELLOSA; MANZOLI, 2009).

Diante do exposto até o momento, pode-se afirmar que a inclusão é para todos e a responsabilidade de incluir também precisa ser, por isso, buscar na legislação brasileira aspectos que auxiliem no processo de inclusão universitária é essencial para aluno e instituição, conforme apresentado a seguir.

\section{A deficiência diante da legislação brasileira}

Inserido no contexto dos direitos sociais e elevado constitucionalmente a direito fundamental, a educação é um direito de todos, cabendo ao Estado e a família, juntamente com o incentivo da sociedade, promovê-la, visando o pleno desenvolvimento da pessoa, seu preparo para o exercício da cidadania e qualificação para o trabalho. (Art. 205, CF), sendo dever do Estado o “atendimento educacional especializado aos portadores de deficiência, preferencialmente na rede regular de ensino" (Art. 208, III, CF) 
Em atenção ao princípio da igualdade, que dispõe que todos são iguais perante a lei, sem distinção de qualquer natureza, a todos deve ser oferecido uma educação digna, para que não sofram prejuízos de ordem psicológica, social e moral ao longo da vida.

Nesse sentido, a educação deve beneficiar todos que dela necessitem, abrangendo assim as pessoas com deficiência, que precisam de um sistema de ensino inclusivo, sistema esse que vai muito além do atendimento diferenciado, englobando a extinção de barreiras arquitetônicas, a adaptação dos móveis, bem como docentes habilitados, capazes de adequar as atividades escolares ao aluno com necessidades especiais, sempre estimulando a autonomia e criatividade do discente.

De acordo com o que dispõe a Nota Técnica SEESP/GAB/n ${ }^{\circ} 11 / 2010$, do Ministério da Educação e da Secretaria da Educação Especial, a educação inclusiva precisa estar fundamentada em princípios filosóficos, políticos e legais dos direitos humanos compreendidos não só na mudança de concepção pedagógica, como na formação docente e na gestão educacional para que de fato a efetivação dos direitos possa acontecer. Assim como o próprio nome sugere, a educação inclusiva, ao invés de segregar o aluno deficiente, visa incluí-lo no ambiente de ensino regular, mesmo que para tanto seja necessário disponibilizar recursos que possibilitem o integral acompanhamento do assunto ministrado (FARIAS; CUNHA; PINTO, 2016)

Em relação a trajetória normativa relacionada a educação inclusiva no Brasil, iniciada com a Política Nacional de Educação Especial, publicada em 1994, o acesso às classes de ensino regular era condicionada a necessidade do aluno deficiente em acompanhar e desenvolver suas atividades seguindo o mesmo ritmo de alunos ditos normais sendo tal imposição na verdade um verdadeiro método de exclusão, já que permitia o ingresso no sistema regular de ensino de apenas uma pequena parcela dos alunos com deficiência.

No cenário internacional, a educação inclusiva ganhou notoriedade a partir de 1994, por meio da declaração elaborada na Conferência Mundial sobre Educação Especial, realizada em Salamanca, cidade espanhola que deu origem ao referido documento e reconhecida como um dos principais manuscritos internacionais sobre o assunto, a Declaração de Salamanca relatou a importância da inclusão educacional das pessoas com deficiência, defendendo que as instituições de ensino se adequassem as necessidades dos indivíduos nelas matriculados (SANTOS; TELES, 2012).

Como um dos países signatário da Declaração de Salamanca, o Brasil se comprometeu a efetuar políticas públicas para inserir as pessoas deficiência na 
sociedade, passando a editar leis nesse sentido, como a Lei de Diretrizes e Bases da Educação Nacional (LDB, Lei nº 9.394/1996) aprovada em dezembro de 1996. Merece destaque ainda a regulamentação da lei sobre a Política Nacional para a Integração da Pessoa Portadora de Deficiência (Decreto $n^{\circ}$ 3.298/1999), que definiu a educação especial como "modalidade de educação escolar que permeia transversalmente todos os níveis e as modalidades de ensino" (Art. 24, II), ressaltando a possibilidade dos estabelecimentos de ensino regular receberem apoio especializado, quando necessário (Art. 15, III); Resolução CNE/CEB No 2, instituída em 2001 sobre as Diretrizes Nacionais para a Educação Especial na Educação Básica, determinando que caberia as escolas a organização para receber todos os alunos, assegurando assim as condições necessárias para uma educação de qualidade (Art $\left.2^{\circ}\right)$.

Nesse mesmo ano, o recém aprovado Plano Nacional da Educação (PNE, Lei 10.172), destacou a necessidade da construção de escolas inclusivas, e a Convenção Interamericana para a Eliminação de Todas as Formas de Discriminação contra as Pessoas Portadoras de Deficiência (Convenção de Guatemala), inserida no país pelo Decreto $n^{\circ}$ 3.956, elencou atitudes relacionada a deficiência, consideradas discriminatórias (HERMIDA, 2006).

Alavancando ainda mais a inclusão educacional e social no país, a Língua Brasileira de Sinais passou a ser reconhecida legalmente como meio de comunicação e Expressão (Lei $\mathrm{n}^{\circ}$ 10.436/02) e políticas públicas foram implantadas em vários municípios brasileiros, no sentido de remodelar o ensino regular, de acordo com os critérios da educação inclusiva. Em continuidade ao itinerário legislativo, no ano de 2004, o Decreto $n^{\circ}$ 5.296/04, regulamentou as leis 10.048/00 e 10.098/00, que aludem respectivamente sobre o atendimento prioritário e normas gerais de acessibilidade às pessoas portadoras de deficiência ou com mobilidade reduzida.

Em 2006, um trabalho realizado pela UNESCO, juntamente com os Ministérios da Educação e da Justiça, bem como a Secretaria Especial dos Direitos Humanos, foi lançado o Plano Nacional de Educação em Direitos Humanos, onde se discutiu ações afirmativas para possibilitar a inclusão, acesso e permanência das pessoas deficiências na educação superior.

No cenário internacional, remodelando por completo a proteção das pessoas com deficiência, foi aprovada em março de 2007, pela Organização das Nações Unidas (ONU), a Convenção sobre os Direitos das Pessoas com Deficiência (2010). 
Dissociando do tradicional conceito patológico, por muito tempo utilizado, a Convenção de 2010, define pessoas com deficiência como "aquelas que têm impedimentos de longo prazo de natureza física, mental, intelectual ou sensorial, os quais, em interação com diversas barreiras, podem obstruir sua participação plena e efetiva na sociedade em igualdades de condições com as demais pessoas" (CONVENÇÃO..., art. $1^{\circ}$ ), dando atenção especial às barreiras sociais que obstam a plena atuação da pessoa com deficiência em sociedade.

No mesmo sentido Araujo (1994, p.24) afirma que o que define tais pessoas “[...] não é a falta de um membro, nem visão ou audição reduzida. O que caracteriza a pessoa portadora de deficiência é a dificuldade de se relacionar, de se integrar na sociedade" e precisa ser entendida de acordo com o grau de dificuldade da integração social, não podendo ser apenas resultado da falha sensorial ou motora.

A Convenção inovou ainda por vincular os países signatários ao que se refere à proteção das pessoas com deficiência, já "que até então o que havia eram normas de soft law, sem qualquer cunho jurídico-obrigacional" (MAZZUOLI, 2014) e faz referência a Flávia Piovesan, afirma que importante inovação da Convenção:

Está no conceito de "reasonable accommodation", que aponta para o dever do Estado "de adotar ajustes, adaptações, ou modificações razoáveis e apropriadas para assegurar às pessoas com deficiência o exercício dos direitos humanos em igualdade de condições com as demais". Daí entender que a violação desse dever representa violação de direitos humanos dessas pessoas, tanto na esfera pública como na privada (apud MAZZUOLI, 2014, p.297).

Em relação ao acesso do ensino superior, a Convenção expressamente dispõe que os Estados Partes devem assegurar o acesso ao ensino superior em geral para as pessoas com deficiência, bem como treinamentos profissionais, educação para adultos e formação continuada sem discriminação e em igualdade de condições (Art.24). No Brasil, o documento foi promulgado por meio do Decreto $n^{\circ}$ 6.949, em agosto de 2009 (BRASIL, 2010) com status equivalente a emenda constitucional (Decreto $\mathrm{n}^{\circ}$ 186/2008), o que significa que todas as normas do ordenamento jurídico que versem sobre pessoas com deficiência, deverão se adequar ao conteúdo da Convenção, sob pena de ser considerada inconstitucional. A incorporação dela ainda vinculou os três poderes da República Federativa do Brasil, passando a ser observada na elaboração de leis, atos da Administração Pública e decisões proferidas pelo judiciário. 
Nesse sentido, programas relacionados à abolição de barreiras arquitetônicas, reconhecimento da educação especial como modalidade da educação que deve ser assegurada em todos os níveis de ensino e preferencialmente na rede regular de ensino, atendimento preferencial em instituições financeiras, repartições públicas e empresas concessionárias de serviços públicos, bem como a substituição de termos como "portadores de deficiência", por "pessoa com deficiência", são alguns exemplos concretos da utilização da Convenção nos mais diversos setores. Resultado da incorporação dela sobre os Direitos das Pessoas com Deficiência no ordenamento jurídico nacional, aliado ao objetivo de proporcionar condições de igualdade a essa parcela da população muitas vezes discriminada e tolhida em seus direitos mais fundamentais, foi inserida na legislação brasileira a Lei de Inclusão da Pessoa com Deficiência, também conhecida como Estatuto da Pessoa com Deficiência (FARIAS; CUNHA; PINTO, 2016; STOLZE, 2015).

Sancionada em 06 de julho de 2015 e em vigor desde 02 de janeiro de 2016, a Lei 13.146 instituiu no ordenamento brasileiro citado acima, conceituando pessoa com deficiência aquela que, a longo prazo, tem impedimento de natureza física, mental, intelectual ou sensorial, capaz de dificultar sua participação na sociedade. A nova lei protagoniza a mais intensa regulamentação pátria sobre a promoção dos direitos das pessoas com deficiência e complementa o ciclo legislativo iniciado com a Constituição Federal de 1988, que assegurou a inclusão das pessoas com deficiência na sociedade.

Concretizando o princípio da dignidade da pessoa humana, bem como o princípio da igualdade como fundamento de uma sociedade democrática, o Estatuto inaugura um sistema normativo inclusivo (STOLZE, 2016), com avanços extremamente importantes, dentre eles o direito ao acesso à educação, utilizando um capítulo inteiro para tratar sobre esse assunto, tamanha a importância do tema.

A Lei 13.146 de 2015 ressalta que a educação, de qualidade e em todos os níveis e modalidades do Sistema Educacional, é direito da pessoa com deficiência, cabendo ao Estado, à família, à comunidade escolar e a sociedade, garantir um ensino inclusivo a essa parcela da população, muitas vezes negligenciada e discriminada, evidenciando ainda a responsabilidade do Poder Público em assegurar, cria, desenvolver, implementar, incentivar, acompanhar e avaliar pesquisas, projetos e práticas pedagógicas que atendam as particularidades do estudante com deficiência e potencialize seu desenvolvimento acadêmico e social, sendo a formação e disponibilização de professores para o atendimento educacional especializado de suma 
importância para a concretização da inclusão da pessoa deficiente na comunidade escolar.

Embasado no Sistema Educacional Inclusivo, o Estatuto menciona ações específicas a serem desenvolvidas para que pessoas com deficiência possam exercer o direito à educação integralmente, como por exemplo, o fornecimento de transporte adaptado, extinção de barreiras arquitetônicas das instituições de ensino, planejamento de estudo de caso, elaboração de plano de atendimento educacional especializado, além da capacitação e qualificação adequada de professores e funcionários para melhor atender alunos com deficiência.

Oportunamente o Estatuto dispõe em seu artigo 28, inciso I sobre o dever do poder público assegurar a educação inclusiva ao longo da vida da pessoa com deficiência, em todos os níveis e modalidades, o que inclui, sem dúvida alguma, o Ensino Superior. A previsão expressa do acesso da pessoa com deficiência ao Ensino Superior, em atenção ao princípio da dignidade da pessoa humana, bem como da igualdade, vem para efetivar o direito social à educação em todos os níveis escolares.

Com efeito, o ingresso da pessoa com deficiência ao ensino superior exige a presença de profissionais capacitados (docentes e funcionários), pensando nisso, o próprio Estatuto determina a inclusão de temas relacionados à pessoa com deficiência na grade de cursos superiores, das mais variadas áreas de conhecimento, objetivando assim que o futuro docente saia da graduação sabendo como transmitir o conhecimento e a informação ao aluno deficiente. (art. 28, XIV da mesma Lei).

Como forma de efetivar o direito à educação, o Estatuto impõe ao Poder Público o dever de disponibilizar profissionais de apoio escolar, que são aquelas pessoas que exercem "atividades de alimentação, higiene e locomoção do estudante com deficiência" (art. $3^{\circ}$, XIII). Esses profissionais atuam em todas as atividades necessárias para a inclusão do aluno com deficiência e devem estar disponíveis em todos os níveis e modalidades de ensino, independentemente do ensino ser prestado por instituição pública ou privada (art. $3^{\circ}$, XIII).

Quanto ao oferecimento do ensino por instituições privadas, de qualquer nível e modalidade de ensino, o parágrafo $1^{\circ}$ do artigo 28 da Lei 13.146 de 2015, proíbe a cobrança de valores adicionais na mensalidade, anuidade e matrícula de alunos com deficiência, almejando assim a democratização da educação inclusiva. Interessante mencionar que a referida proibição teve sua (in) constitucionalidade questionada pela 
Confederação Nacional dos Estabelecimentos de Ensino mesmo antes da entrada em vigor do Estatuto.

Através do ajuizamento da ação direta de inconstitucionalidade $\mathrm{n}^{\circ}$ 5357, a Confederação alegou que os artigos $28, \S 1^{\circ}$, e 30 , caput, do estatuto violariam a liberdade de iniciativa, o direito de propriedade e a função social desta, ao determinar a obrigatoriedade da matrícula de pessoas com deficiência, bem como, afrontaria o principio da razoabilidade, ao exigir das instituições privadas inúmeras adaptações para receberem alunos portadores de necessidades especiais, mas proibir expressamente a cobrança de valores adicionais de qualquer natureza desses consumidores, o que provocaria prejuízos gigantescos às instituições de ensino, com o consequente repasse dos referidos gastos aos demais alunos, ou pior, o encerramento das atividades de muitas delas.

A entidade asseverou ainda que, caberia ao Poder Público disponibilizar a educação especial aos portadores de deficiência e não repassar essa obrigação constitucional às instituições privadas, com o agravante de vedar qualquer cobrança de valores adicionais pelo atendimento especializado, não podendo a Lei exigir das instituições privadas aquilo que o próprio Estado é incapaz de oferecer. Em resposta, o Supremo Tribunal Federal, julgou improcedente a ação direta de inconstitucionalidade, reconhecendo, a constitucionalidade dos dispositivos normativos questionados, com a consequente obrigatoriedade das instituições privadas de inserir pessoas deficientes no ensino regular e providenciar as adaptações necessárias sem que o custo seja repassado de qualquer forma aos alunos. O Supremo ressaltou que a iniciativa privada, ao oferecer o serviço educacional não pode "fazê-lo de forma ilimitada ou sem responsabilidade", devendo sempre observar as normas gerais de educação nacional, previstas, inclusive, na própria Constituição Federal.

O relator da ação, ministro Fachin afirmou ainda que não cabe ao ensino privado recusar a matrícula do aluno deficiente, privando "os estudantes - com e sem deficiência - da construção diária de uma sociedade inclusiva e acolhedora, transmudando-se em verdadeiro local de exclusão, ao arrepio da ordem constitucional vigente" (BRASIL, 2016).

O desfecho da ação direta de Inconstitucionalidade n.5357 foi recebido como uma grande vitória pelos brasileiros com alguma deficiência e representou a concretização de vários dispositivos constitucionais, da Convenção Internacional sobre os Direitos das Pessoas com Deficiência e principalmente do Estatuto da Pessoa com 
deficiência (FARIAS; CUNHA; PINTO, 2016; STOLZE, 2016) que representa a mais nova arma legislativa para a efetiva inclusão social da pessoa com deficiência.

Ainda em relação ao ingresso da pessoa com deficiência ao ensino superior, o Estatuto teve o cuidado de estabelecer algumas regras relacionadas ao processo seletivo para ingresso e permanência nos cursos oferecidos por instituições de ensino superior, públicas ou privadas.

Atendimento preferencial nas dependências das instituições de ensino superior, disponibilização de formulário de inscrição que possua campo para que o aluno informe os recursos de acessibilidade que serão necessários para a realização da prova, bem como dilação de tempo, tanto na realização da seleção como nas futuras atividades acadêmicas, são algumas regras estabelecidas pelo Estatuto para que a instituição de ensino superior receba o aluno com deficiência da melhor forma.

Naturalmente que na difícil empreitada para eliminar a discriminação e segregação da pessoa com deficiência, o acesso à educação em todos os níveis e modalidades representa um grande aliado.

Ademais, constitucionalmente estabelecida como direito fundamental, a educação se mostra um vetor eficaz para a redução das desigualdades sociais (art. $3^{\circ}$, III, CF) e construção de uma sociedade mais solidária (art. $3^{\circ}$, IV).

Nesse contexto é certo que, em conjunto com o ensino fundamental e médio, o acesso ao ensino superior possibilita o pleno desenvolvimento intelectual e social da pessoa com deficiência, além de refletir a concretização da democracia e justiça, quando oferecido e adaptado às necessidades de cada um.

Resultado de um lento e árduo processo legislativo, todas as normas jurídicas expostas ao longo desse artigo representam na verdade um primeiro passo para a efetivação da educação inclusiva, principalmente no campo do ensino superior, devendo somar-se à formação de uma sociedade consciente e inclusiva e, sobretudo do desenvolvimento de instituições de ensino superior dispostas a quebrar os paradigmas necessários para exterminar todas as barreiras que dificultam o acesso e permanência de pessoas com deficiência às cadeiras universitárias, sejam elas de ordem arquitetônicas, sociais, ou pedagógicas,

\section{Considerações finais}


É possível perceber que quando se fala em inclusão e acessibilidade não se pode tratar apenas das questões de estrutura e acesso físico. No Ensino Superior, as barreiras são diversas, abrangendo outros campos que precisam ser considerados em sua totalidade a fim de receber e manter o aluno com deficiência até a conclusão do curso.

Se por muito tempo viveram à margem da sociedade, na atualidade o que se vê são grandes evoluções retratadas principalmente na condição pessoal de cada pessoa com deficiência. A estima, o sonho, os objetivos são muito maiores devido as melhorias que estão conseguindo diante da sociedade, o que não significa que a luta pelos direitos esteja no fim. Ao contrário, ainda é preciso muito esforço para a que a deficiência fique apenas na condição limitante do ser humano. Estar não significa ser e diante disso é que a sociedade precisa buscar incluir quem nunca deveria ter sido excluído.

Os movimentos pela educação precisam continuar em todos os níveis e em paralelo as instituições de ensino precisam ser atualizadas para receber essa parcela da população que cresce e necessita de oportunidades. A reestruturação do ensino superior precisa ser urgente e embora já apresente avanços ainda estão longe de atender na totalidade. Há muito o que ser feito em termos estruturais, físicos e principalmente nas ações pedagógicas e na gestão, uma vez que são essas as grandes responsáveis pela inclusão desse público no ensino superior.

Em termos legislativos é certo que, resultado de um lento e árduo processo, todas as normas jurídicas expostas ao longo desse artigo representam na verdade um primeiro passo para a efetivação da educação inclusiva, principalmente no campo do ensino superior, devendo somar-se à formação de uma sociedade consciente e inclusiva e, sobretudo do desenvolvimento de instituições de ensino superior dispostas a quebrar os paradigmas necessários para exterminar todas as barreiras que dificultam o acesso e permanência de pessoas com deficiência às cadeiras universitárias, sejam elas de ordem arquitetônicas, sociais, ou pedagógicas, cabendo ainda a fiscalização maciça de todos da sociedade, especialmente dos órgãos públicos incumbidos de fiscalizar a efetivação dos direitos das pessoas com deficiência.

Pensar na universalização do ensino é ver a todos como pertencentes de um sistema que pode, deve e precisa oferecer qualidade e igualdade para que a sociedade evolua e se torne melhor.

\section{Referências}


AMIN, A. R. Evolução histórica do direito da criança e do adolescente. IN: MACIEL, K. R. F. L. A. (Org). Curso de Direito da Criança e do Adolescente: aspectos teóricos e práticos. 3 ed. São Paulo: Lúmen Júris, 2008.

ARAUJO, L. A. D. A proteção constitucional das pessoas de deficiência. Brasília: Corde, 1994.

ASSOCIAÇÃO BRASILEIRA DE NORMAS TECNICAS - ABNT. NBR 9050: 1994. Acessibilidade de pessoas portadoras de deficiências a edificações, espaço, mobiliário e equipamento urbanos. Rio de Janeiro: ABNT, 2004.

AUAD, J. C.; CONCEIÇÃO, M. I. G. Educação Especial Superior: o exemplo da Universidade de Brasília. Revista Educação Especial, Santa Maria, v.22, n.34, p.213224, maio/ago, 2009. Disponível em:< <https://periodicos.ufsm.br/educacaoespecial/article/view/274/133>. Acesso em: 20 mar. 2017.

BAÚ, M. A. Avaliação da acessibilidade no ensino Superior: UTFPR - Campus Medianeira. 123 f. Dissertação (Mestrado) - Faculdade de Filosofia e Ciências, Universidade Estadual Paulista, Marília, 2015. Disponível em:< http://www.marilia.unesp.br/Home/Pos-

Graduacao/Educacao/Dissertacoes/bau_m_a_me_mar.pdf> Acesso em: 10 mar. 2017.

BRASIL. Supremo Tribunal Federal. Escolas particulares devem cumprir obrigações do Estatuto da Pessoa com Deficiência, decide STF. Quinta-feira, 09 de junho de $2016 . \quad$ Disponível em:< http://www.stf.jus.br/portal/cms/verNoticiaDetalhe.asp?idConteudo=318570>. Acesso em: 20 abr. 2017.

BRASIL. Lei n.13.146, de 6 de julho de 2015. Institui a Lei Brasileira de Inclusão da Pessoa com Deficiência (Estatuto da Pessoa dom Deficiência). Disponível em: <http://planalto.gov.br/ccivil_03/Ato2015-2018/2015/Lei/L13146.htm > Acesso em: 16 mar. 2017.

BRASIL. Ministério da Educação. Secretaria de Educação Especial. Nota Técnica SEESP/GAB/N.11/2010 de 7 de maio de 2010. Dispõe de Orientações para a institucionalização da Oferta do Atendimento Educacional Especializado - AEE em Salas de Recursos Multifuncionais, implantadas nas escolas regulares. Brasília: MEC, 2010. Disponível em: <http://portal.mec.gov.br/index.php?option $=$ com_docman\&view $=$ download\&alias $=529$ 4-notatecnica-n112010\&category_slug=maio-2010-pdf\&Itemid=30192 > Acesso em: 20 mar. 2017.

BRASIL. Secretaria de Educação Especial. Marcos Político-Legais da Educação Especial na Perspectiva Inclusiva. 2010. Disponível em:< http://portal.mec.gov.br/index.php?option=com_docman\&view=download\&alias=6726marcos-politicos-legais\&Itemid=30192> Acesso em: 20 mar. 2017.

BRASIL. Secretaria de Direitos humanos. Convenção sobre os direitos das pessoas com deficiência. Decreto legislativo n. 186/2008 e n. 6.949/2009. Brasília, 2010. Disponível 
em:

www.pessoacomdeficiencia.gov.br/app/sites/default/files/publicacoes/convencaopessoa scomdeficiencia.pdf> Acesso em: 20 abr. 2017.

BRASIL. Decreto $N^{\mathbf{0}}$ 5.296, de 02 de dezembro de 2004: regulamenta as leis 10.048/00 e 10.098/00. Disponível em: <www.planalto.gov.br/ccivil/_ato20042006/2004/decreto/d5296.htm >. Acesso em: 20 out. 2005

BRASIL. Lei $\mathbf{n}^{\mathbf{0}}$ 10.436, de 24 de abril de 2002. Dispõe sobre a Língua Brasileira de Sinais - Libras e dá outras providências. Brasília, 2002. Disponível em:< http://www.planalto.gov.br/ ccivil_ 03/Leis/2002/L10436.htm> Acesso em: 10 mar. 2017.

BRASIL. Decreto Federal n.5.296 de 2/12/2004. Regulamenta as Leis nos 10.048, de 8 de novembro de 2000, que dá prioridade de atendimento às pessoas que especifica, e 10.098, de 19 de dezembro de 2000, que estabelece normas gerais e critérios básicos para a promoção da acessibilidade das pessoas com deficiência ou com mobilidade reduzida, e dá outras providências. Diário oficial da União. Brasília, 3 dez. 2004.

BRASIL. LDB nacional. [Recurso eletrônico]: Lei de Diretrizes e Bases da Educação Nacional: Lei n. 9394, de 20 de dezembro de 1996, que estabelece as diretrizes e bases da educação nacional. 11.ed. Brasília: Câmara dos Deputados: edições Câmara, 2015. (Série Legislação, n.159).

CANDIDO, E. A. P.; NASCIMENTO, C.R.S.; MARTINS, M.F.A. Acessibilidade na educação superior também envolve o trabalho pedagógico. RIAEE - Revista IberoAmericana de Estudos em Educação, v. 11, n. esp.2, p.1017-1033, 2016. Disponível em:< http://seer.fclar.unesp.br/iberoamericana/article/view/8940/5883> Acesso em: 29 mar. 2017.

CARVALHO, C. L. C. Pessoas com deficiência no ensino superior: percepções dos alunos. 2015. 91f. Dissertação de Mestrado, Faculdade de Economia, Administração e Contabilidade. Universidade de São Paulo, SP. Disponível em:< http://www.teses.usp.br/teses/disponiveis/12/12136/tde-04092015-104118/pt-br.php> Acesso em: 15 mar. 2017.

CASTRO, S. F.; ALMEIDA, M. A. Ingresso e permanência de alunos com deficiência em universidades públicas brasileiras. Revista Bras. Ed. Esp., Marília, v.20, n.2, p.179-194, abr.-jun.2014. Disponível em:< http://www.scielo.br/scielo.php?pid=S141365382014000200003\&script=sci_abstract\&tlng=pt > Acesso em 15 mar. 2017.

CASTRO, S. F. Ingresso e permanência de alunos com deficiência em Universidades Públicas Brasileiras. 2011. 278f. Tese (Doutorado em Educação Especial) Universidade Federal de São Carlos, São Carlos, 2011.

CAVAZZANI, A.L.M. Um estudo sobre a exposição e os expostos da Vila Nossa Senhora da Luz dos Pinhais de Curitiba. 2005. Dissertação de mestrado em História. Universidade Federal do Paraná. Disponível em: $<$ http://www.dominiopublico.gov.br/pesquisa/DetalheObraForm.do?select_action=\&co _obra=148125>. Acesso em: 20 jan. 2010. 
CONVENÇÃO sobre os Direitos das Pessoas com Deficiência: Protocolo Facultativo à Convenção sobre os Direitos das Pessoas com Deficiência: Decreto Legislativo $\mathrm{n}^{\circ}$ 186, de 09 de julho de 2008: Decreto ${ }^{\circ}$ 6.949, de 25 de agosto de 2009. $4^{\text {a }}$ ed., rev. e atual. Brasília: Secretaria de Direitos Humanos, 2010. 100p. Disponível em: < http://www.pessoacomdeficiencia.gov.br/app/sites/default/files/publicacoes/convencaop essoascomdeficiencia.pdf >. Acesso em: 10 mar. 2017.

DEIMLING, N. M.; MOSCARDINI, S. F. Inclusão escolar: politica, marcos históricos, avanços e desafios. Revista online de Política e Gestão Educacional, n.12, 2012. Disponível em:< http://seer.fclar.unesp.br/rpge/article/view/9325/6177> Acesso em: 25 mar. 2017.

FARIAS, C. C.; CUNHA, R. S.; PINTO, R. B. Estatuto da pessoa com deficiência comentado. 2.ed. rev. ampl. atual. Salvador: Juspodium, 2016.

FREITAS, S. N.; TEIXEIRA, C. T.; RECH, A. J. D. Alunos com deficiência em situação de acolhimento institucional: desafios para a gestão e a inclusão escolar. RIAEE - Revista Ibero-Americana de Estudos em Educação, v. 11, n. 4, p.21042124, $2016 . \quad$ Disponível em:< http://seer.fclar.unesp.br/iberoamericana/article/view/8214/6048>. Acesso em: 06 abr. 2017.

FUNDAÇÃO DORINA NOWILL PARA CEGOS. Deficiência visual. São Paulo [s.d]. Disponível em:<http://fundacaodorina.org.br/deficiencia-visual/ > Acesso em: 17 mar. 2017.

HERMIDA, J. F. O Plano Nacional de Educação (Lei 10.172), de 9 de janeiro de 2001. Educ. rev., Curitiba, n. 27, p. 239-258, jun. 2006. Disponível em: <http://www.scielo.br/scielo.php?script=sci_arttext\&pid=S0104-40602006000100015> Acesso em: 20 abr. 2017.

KROTON. Núcleo de Educação Inclusiva. Formação em Educação Inclusiva. [Material de curso corporativo].65f. Londrina: Editora e Distribuidora Educacional, 2017.

MAZZUOLI, V. O. Curso de direitos humanos. Rio de Janeiro: Forense; São Paulo: Método, 2014.

MUTO, J. H. D.; CAMPOS, J. A. P. P.; MELO, E. M. O aluno público alvo da educação especial no ensino médio: as relações entre família e escola. Revista online de Política e Gestão Educacional, v. 20, n. 1, 2016, p.49-69, 2016. Disponível em:< http://seer.fclar.unesp.br/rpge/article/view/9392/6243>. Acesso em: 20 mar. 2017.

PERTILE, E. B.; ROSSETTO, E. Trabalho e formação docente para o atendimento educacional especializado. RIAEE - Revista Ibero-Americana de Estudos em Educação, v.10, n.4, p. 1186- 1198, 2015. Disponível em:<http://seer.fclar.unesp.br/iberoamericana/article/view/6219/5577>. Acesso em: 05 abr. 2017. 
PIOVESAN, F. A proteção internacional dos direitos das mulheres, p.297 IN: MAZZUOLI, V. O. Curso de direitos humanos. Rio de Janeiro: Forense; São Paulo: Método, 2014.

SANTOS, A. R.; TELES, M. M. Declaração de Salamanca e educação inclusiva. In: Simpósio Educação e Comunicação, 3, 2012, [S.L]. Anais ..., 2012. p. 7787. Disponível em:<http://geces.com.br/simposio/anais/anais-2012/Anais-077087.pdf>. Acesso em: 28 abr. 2017.

STOLZE, P. Estatuto da Pessoa com Deficiência e sistema de incapacidade civil. Revista Jus Navigandi, Teresina, v.20, n.4411, 30 jul.2015.Disponível em: <https://jus.com.br/artigos/41381>. Acesso em: 28 abr. 2017

VELLOSA, S. C. L.; MANZOLI, L. As tendências educacionais politizadoras do processo inclusivo: acertos e desacertos. Revista online de Política e Gestão Educacional, $\quad$ n.6, 2009. Disponível em: <http://seer.fclar.unesp.br/rpge/article/view/9250/6132>. Acesso em: 02 jan. 2017.

\section{Como citar este artigo:}

WELLICHAN, Danielle S. Pinheiro.; SOUZA, Camila da Silva. A inclusão na prática: alunos com deficiência no Ensino Superior. Revista on line de Política e Gestão Educacional, Araraquara, v.21, n.1, p. 146-166, 2017. Disponível em: <http://dx.doi.org/10.22633/rpge.v21.n.1.2017.9786>. ISSN: 1519-9029.

Submetido em: 30/03/2017

Aprovado em: 30/04/2017 